\title{
Uso do método do disco e da altura da planta para estimar a massa de forragem em relvado de Cynodon spp.
}

\author{
Rising plate meter and plant height to estimate the herbage mass in Cynodon ssp. Swards
}

\author{
Domingos Sávio Campos Paciullo ${ }^{1}$ Luiz Januário Magalhães Aroeira² \\ Antônio Carlos Cóser ${ }^{2}$ Rodrigo Carvalho Cardoso ${ }^{3}$
} \begin{abstract}
RESUMO
A altura das plantas $(A P)$ e a altura comprimida da vegetação por disco (AD) foram usadas para estimativas
da massa de forragem antes e depois do pastejo em uma pastagem mista de capim-coastcross-1 (Cynodon dactylon (L.) Pears) e capim-estrela (Cynodon nlenfuensis var. nlenfuensis), manejada rotativamente. Foram estabelecidas equações de regressão entre a altura das plantas ou a altura comprimida da vegetação por disco de raio conhecido e o peso seco de forragem. Para a massa de forragem antes do pastejo, os coeficientes de determinação variaram de 0,70 a 0,87 com a $A D$ e de 0,58 a 0,70 com a AP. Para a massa de forragem após o pastejo, observaram-se piores ajustes das equações, tendo em vista os baixos coeficientes de determinação $(0,13$ a 0,46). A AD apresentou melhores resultados para estimar a massa de forragem antes do pastejo. As técnicas apresentaram baixa confiabilidade para estimativas da massa de forragem após o pastejo.
\end{abstract}

Palavras-chave: altura da planta, dupla-amostragem, método do disco, produção de forragem.

\section{ABSTRACT}

The techniques of plant height $(\mathrm{PH})$ and rising plate meter (RPM) were used to estimate the herbage mass before and after grazing in Cynodon dactylon (L.) Pears and Cynodon nlemfuensis var. nlenfuensis mixture pasture, under rotational system. Regression equations between sward surface heigth or compressed sward heigth by disk and the herbage dry weight were established. To herbage mass before grazing, the coefficients of determination $\left(r^{2}\right)$ ranged from 0.70 to 0.87 for RPM and from 0.58 to 0.70 for $P H$. The residual herbage mass was poorly associated with heights of plant or disk ( $r^{2}$ values varying from 0.13 to 0.46). The RPM showed better results to estimate the herbage mass before grazing than PH. The techniques could not be recomended to estimated herbage mass after grazing.

Key words: sward height, double-sampling, rising-plate meter, herbage production.

A determinação da disponibilidade de forragem é de grande importância para orientar o manejo das forrageiras usadas em sistemas de exploração pecuária baseados no uso de pastagem. A necessidade de um método rápido e preciso para estimativa da quantidade de forragem em áreas extensas é largamente reconhecida. Medições da altura da forrageira (GONZALES et al., 1990; OLIVEIRA et al., 2001), realizadas com auxílio de régua graduada, e altura comprimida da vegetação por disco de raio conhecido (EARLE \& McGOWAN, 1979), permitem estimativas rápidas da disponibilidade de forragem e imediata utilização dos resultados no ajuste da carga animal (BRANSBY et al., 1977).

O objetivo deste estudo foi avaliar duas técnicas (altura das plantas e altura comprimida da vegetação pelo disco) para estimativa da quantidade de forragem em pré e pós-pastejo, em pastagem de gramíneas do gênero Cynodon.

O trabalho foi conduzido na Embrapa Gado de Leite, no Município de Coronel Pacheco, Minas Gerais. Foi usada uma área de pastagem mista de capimcoastcross-1 (Cynodon dactylon (L.) Pears) e capimestrela (Cynodon nlemfuensis), dividida em piquetes

${ }^{1}$ Engenheiro Agrônomo, Bolsista Recém-doutor do CNPq, Embrapa Gado de Leite, Rua Eugênio do Nascimento, 610, Dom Bosco, 36038-330, Juiz de Fora, MG. E-mail: dscp@terra.com.br Autor para correspondência

${ }^{2}$ Pesquisador Embrapa Gado de Leite, Rua Eugênio do Nascimento, 610. Dom Bosco, Juiz de Fora, MG

${ }^{3}$ Estudante Doutorado em Zootecnia, Universidade Federal de Lavras, Lavras, Minas Gerais. 
medindo $470 \mathrm{~m}^{2}$ e manejada rotativamente com vacas Holandesas em lactação. A pastagem, estabelecida em 1992, vem sendo usada para estudos sobre a produção de leite de vacas em regime de pastejo. O cronograma de pastejo utilizado estava pré-definido com o sistema de rotação vigente e constituiu-se em um dia de ocupação/piquete e período de descanso variando de 25 a 35 dias, dependendo da época do ano. A área foi fertilizada com doses de $200 \mathrm{~kg}$ de $\mathrm{N}$ e de $\mathrm{K}_{2} \mathrm{O}$ e $50 \mathrm{~kg}$ de $\mathrm{P}_{2} \mathrm{O}_{5}$ por ha/ano, divididas em aplicações bimestrais.

As avaliações foram realizadas em novembro/2000 e abril/2001. Estabeleceram-se equações de regressão linear entre a altura das plantas (AP) ou a altura comprimida da vegetação por um disco de raio conhecido (AD) e o peso seco da forragem verde delimitada pelo disco.

Para as amostragens, feitas antes (disponível) e após (resíduo) o pastejo dos animais, foram escolhidos 20 pontos em cada piquete que representassem as diferentes condições da vegetação. As avaliações foram feitas em quatro piquetes utilizados simultaneamente. Para a AD foi usado um disco de metal $\left(0,25 \mathrm{~m}^{2}\right)$ com furo no centro que permitiu que o mesmo deslizasse por uma haste graduada. Em cada amostragem, foram registradas as distâncias entre o topo da vegetação comprimida pelo disco e a superfície do solo. Para a AP, foram medidas as distâncias do solo ao topo da vegetação, nos mesmos pontos usados para a AD. Tais medidas foram realizadas com auxílio de régua graduada. A forragem localizada sob o disco foi cortada rente ao solo e o material coletado foi pesado; deste foi retirada uma subamostra para secagem em estufa a $65^{\circ} \mathrm{C}$ e obtenção do peso da matéria seca da amostra. Com os dados pareados de altura (X) e massa de forragem (Y) ajustaram-se equações de regressão. Os valores dos coeficientes de regressão das equações foram testados pelo teste "t" em nível de 5\% de probabilidade de erro.

Para as equações de massa de forragem antes do pastejo, os valores de $\mathrm{r}^{2}$ variaram de $0,58 \mathrm{a}$ 0,87 (Tabela 1). Maiores valores de $\mathrm{r}^{2}$ foram obtidos em março, relativamente aos de novembro. As equações de regressão ajustadas com o conjunto de dados de novembro e março revelaram melhoria no valor de $\mathrm{r}^{2}$, apenas em relação ao valor de novembro, com a AD. Os maiores valores de $\mathrm{r}^{2}$ para a AD indicam que esta apresentou melhor ajuste das equações, do que a AP. O valor de $\mathrm{r}^{2}$ observado em março $(0,87)$, para a $\mathrm{AD}$, está próximo daqueles obtidos por MITCHELL \& LARGE (1983) e GONZALES et al. (1990), para espécies de hábito de crescimento prostrado, respectivamente, de 0,91 e 0,90. Entretanto, os demais valores, sempre abaixo de 0,75 , indicam baixa confiabilidade dos métodos para estimativa da biomassa de forragem disponível na pastagem.

Após o pastejo, os dados apresentaram grande dispersão em torno da regressão, com valores de $r^{2}$ variando de 0,13 a 0,46 (Tabela 1). Em março, a equação de regressão não foi significativa para a $\mathrm{AD}$ $\left(\mathrm{r}^{2}\right.$ de 0,13$)$ e, embora tenha sido significativa para a AP, apresentou baixo $r^{2}(0,20)$. A associação dos dados de novembro e março aumentou os valores de $\mathrm{r}^{2}$, relativamente aos de março, de 0,13 para 0,42 (AD) e de 0,20 para 0,35 (AP). Ainda assim, os baixos valores de $r^{2}$ mostram que as alturas da planta e do disco não foram bons indicadores da biomassa de forragem residual. Este fato pode estar associado à fraca estrutura dos perfilhos remanescentes ao pastejo, os

Tabela 1 - Equações de regressão da massa de forragem antes e após o pastejo (Y, emkg.ha $\left.{ }^{-1}\right)$, em função da altura da planta comprimida pelo disco (AD) e da altura da planta (AP)

\begin{tabular}{llcccc}
\hline \multirow{2}{*}{ Técnica } & Mês & \multicolumn{2}{c}{ Antes do pastejo } & \multicolumn{2}{c}{ Após o pastejo } \\
\cline { 3 - 6 } & & \multicolumn{1}{c}{ Equação de regressão } & $\mathrm{r}^{2}$ & Equação de regressão & $\mathrm{r}^{2}$ \\
\hline \multirow{2}{*}{ Novembro } & $\hat{Y}=1234,2+124,9 * A D$ & 0,70 & $\hat{Y}=1246,5+115,1 * A D$ & 0,46 \\
Altura do disco & Março & $\hat{Y}=-1638,7+226,0 * A D$ & 0,87 & $\hat{Y}=2682,1+82,2^{n s} A D$ & 0,13 \\
& $\begin{array}{l}\text { Novembro }+ \\
\text { março }\end{array}$ & $\hat{Y}=-67,3+174,6 * A D$ & 0,75 & $\hat{Y}=1339,3+129,3 * A D$ & 0,42 \\
Novembro & $\hat{Y}=667,7+99,9 * A P$ & 0,59 & $\hat{Y}=-101,4+107,4 * A P$ & 0,35 \\
& Março & $\hat{Y}=-3262+202,6 * A P$ & 0,70 & $\hat{Y}=1269,0+95,3 * A P$ & 0,20 \\
& $\begin{array}{l}\text { Novembro }+ \\
\text { março }\end{array}$ & $\hat{Y}=-876,1+143,4 * A P$ & 0,58 & $\hat{Y}=-10,9+119,2 * A P$ & 0,35 \\
\hline
\end{tabular}

$*(\mathrm{P}<0,05)$ e ns - não-significativo pelo teste $\mathrm{t}$. 
quais apresentaram baixa resistência à compressão exercida pelo disco (OLIVEIRA et al., 2001). Além disso, a vegetação tombada pelo pisoteio dos animais pode reduzir a acurácia dos métodos indiretos nas estimativas de biomassa de forragem após o pastejo (STOCKDALE \& KELLY, 1984).

A técnica da altura do disco estimou com maior confiabilidade a massa de forragem antes do pastejo, quando comparada à altura da planta. Quando usadas após o pastejo, as técnicas não foram adequadas para estimar a massa de forragem.

\section{REFERÊNCIAS BIBLIOGRÁFICAS}

BRANSBY, D.I.; MATCHES, A.G.; KRAUSE, G.F. Disk meter for rapid estimation of herbage yield in grazing trials. Agronomy Journal, v.69, p.393-396, 1977.

EARLE, D.F.; McGOWAN, A.A. Evaluation and calibration of an automatic rising plate meter foi estimating dry matter yield of pasture. Australian Journal of Experimental Agriculture and Animal Husbandry, v.19, p.337-343, 1979.

GONZALEZ, M.A.; HUSSEY, M.A.; CONRAD, B.E. Plant height, disk, and capacitance meters used to estimate bermudagrass herbage mass. Agronomy Journal, v.82, p.861864, 1990.

MICHELL, P.; LARGE, R.V. The estimation of herbage mass of perennial ryegrass swards: a comparative evaluation of a rising-plate meter and a single-probe capacitance meter calibrated at and above ground level. Grass and Forage Science, v.38, p.295-299, 1983.

OLIVEIRA, D.E. et al. Estimating herbage mass in stargrass (Cynodon nlenfuensis var. nlenfuensis) using sward surface height and the rising plate meter. In: INTERNATIONAL GRASSLAND CONGRESS, 19., 2001, São Pedro. Proceedings... Piracicaba : FEALQ, 2001. p.1055-1056.

STOCKDALE, C.R.; KELLY, K.B. A comparison of a risingplate meter and an electronic capacitance meter for estimating the yield of pastures grazed by dairy cows. Grass and Forage Science, v.39, p.391-394, 1984. 